\title{
Measuring Natural Selection on Genotypes and Phenotypes in the Wild
}

\author{
C.R. LINNEN AND H.E. HoEKSTRA \\ Department of Organismic and Evolutionary Biology and Museum of \\ Comparative Zoology, Harvard University, Cambridge, Massachusetts 02138 \\ Correspondence: hoekstra@oeb.harvard.edu
}

\begin{abstract}
A complete understanding of the role of natural selection in driving evolutionary change requires accurate estimates of the strength of selection acting in the wild. Accordingly, several approaches using a variety of data-including patterns of DNA variability, spatial and temporal changes in allele frequencies, and fitness estimates - have been developed to identify and quantify selection on both genotypes and phenotypes. Here, we review these approaches, drawing on both recent and classic examples to illustrate their utility and limitations. We then argue that by combining estimates of selection at multiple levels-from individual mutations to phenotypes - and at multiple timescales - from ecological to evolutionary - with experiments that demonstrate why traits are under selection, we can gain a much more complete picture of the adaptive process.
\end{abstract}

To account for adaptation - the remarkably precise fit between organisms and their environments-Darwin (1859) and Wallace (1858) independently proposed the theory of evolution by natural selection. One hundred and fifty years later, we have amassed a large body of theoretical and empirical work that extensively describes and documents natural selection, yet we are still largely ignorant as to how, exactly, natural selection acting on beneficial mutations leads to adaptation (Orr 2005). There are many fundamental questions that remain largely unanswered. These include: Where do most adaptive genetic variants come fromancestral variation or de novo mutation? How strong is selection, on average, and does its strength vary for different types of phenotypic traits? Does the strength of selection change in a predictable way as mutations are fixed and populations approach phenotypic optima? Do most adaptations involve a small number of genes with large phenotypic effects or many genes of small effect? To what extent do competing ecological demands, genetic linkage, and pleiotropy constrain adaptation? Finally, how often does natural selection rely on the same genes and/or mutations to drive convergent evolution? Answering these questions is challenging because it requires knowing the precise phenotypic targets of selection, identifying the genetic loci contributing to those adaptive traits, and measuring the strength of selection acting on both phenotypes and genotypes.

In a now classic book, Endler (1986) compiled evidence for selection in natural populations from a diversity of species measured using a variety of approaches. This and other widely used references (see, e.g., Hartl and Clark 2007) classify approaches to estimating selection into two broad categories: those that can be applied to discrete polymorphisms and those for continuous characters. These approaches have developed largely in isolation (but see Kimura and Crow 1978; Milkman 1978); however, with increased power to link genotype to phenotypes in natural populations, it is now possible to estimate selec- tion at multiple levels of biological organization simultaneously and thus use a diverse set of complementary methods to better understand adaptation in the wild.

Here, we discuss approaches used to estimate the strength of selection, drawing on both classic and recent examples to illustrate their utility. Because of its association with adaptation and the evolution of novel forms and functions, we focus on positive selection. In the first four sections, we describe methods for estimating the strength of selection on genotypes and phenotypes using four distinct types of data: (1) within-generation fitness estimates from individuals bearing different genotypes and/or phenotypes, (2) changes in allele frequencies or phenotypic means over multiple generations, (3) changes in allele frequencies or phenotypic means in space, and (4) DNA sequence data from genes that contribute to phenotypic differences in natural populations. For clarity, we divide the first two sections by the type of trait variation (genotypic or phenotypic) under study. These diverse approaches allow us to measure selection at multiple levels - from single-nucleotide changes to quantitative traits - and at multiple timescales - from ecological to evolutionary. However, none can tell us why particular traits are under selection; this issue is discussed in a fifth section. Finally, we conclude by discussing how applying multiple methods to traits for which we can make genotype-phenotype and phenotype-fitness links can address fundamental questions regarding the genetics of adaptation in natural populations.

\section{FITNESS DIFFERENCES BETWEEN GENOTYPES OR PHENOTYPES (WITHIN A GENERATION)}

Natural selection need not result in evolution - a change in allele frequencies over time. For example, when phenotypes do not differ in their underlying genotypes or when selection favors heterozygotes, allele frequencies may 
remain the same from one generation to the next. Thus, the most straightforward way to estimate the strength of selection is to focus on a single generation and compare the success of different phenotypes or genotypes at survival and reproduction. This approach requires information regarding the fitness of individuals (or classes of individuals) in a population. Unfortunately, "fitness" is notoriously difficult to define and measure (see Endler 1986; De Jong 1994; McGraw and Caswell 1996; Orr 2009). Therefore, most studies measure components of fitness (e.g., survival to sexual maturity, survival following an environmental change, number of mates, or number of offspring produced) as surrogates for total fitness. Because selection may differ over the course of a single generation or across years (Schemske and Horvitz 1989; Hoekstra et al. 2001; Siepielski et al. 2009), the most comprehensive studies estimate fitness across multiple life stages and are repeated across multiple years; two such examples are described below.

\section{Genotypes}

Selection on a single Mendelian locus, or a discrete polymorphism presumed to be under the control of a single gene, can be quantified using a selection coefficient $(s)$ that describes the intensity of selection against genotypes (or alleles). Specifically, $s$ for a given genotype is equal to $1-w$, where $w$ is the relative fitness of that genotype. The relative fitness for each genotypic class is calculated by dividing the absolute fitness for that class (estimated from survival rates or number of offspring produced, see above) by the highest absolute fitness across all genotypic classes. Traditionally, $s$ has been calculated for discrete morphological characters (see, e.g., Schemske and Bierzychudek 2001) or enzyme polymorphisms (see, e.g., Eanes 1999). More recently, however, advances in genomic technologies and statistical methods for analyzing genotypic and phenotypic data have enabled us to identify genes contributing to variation in quantitative traits (for review, see Mackay 2001; Feder and Mitchell-Olds 2003; Luikart et al. 2003; Erickson et al. 2004; Vasemagi and Primmer 2005; Ehrenreich and Purugganan 2006; Ellegren and Sheldon 2008; Hoffmann and Willi 2008; Naish and Hard 2008; Pavlidis et al. 2008; Stinchcombe and Hoekstra 2008; Mackay et al. 2009; Slate et al. 2009). Thus, it is now possible to estimate selection coefficients for individual quantitative trait loci (QTLs) (see, e.g., Schemske and Bradshaw 1999; Rieseberg and Burke 2001; Lexer et al. 2003a; Mullen and Hoekstra 2008). One such analysis, described below, was performed on a major-effect QTL contributing to adaptive morphological variation in threespine sticklebacks (Gasterosteus aculeatus).

Following the last ice age, marine threespine sticklebacks repeatedly colonized freshwater environments and underwent concomitant losses in bony armor plating (Fig. 1A) (Bell and Foster 1994). Repeated loss in similar environments suggests that selection is responsible for these morphological differences. QTL mapping followed by functional verification via transgenic studies have implicated the gene Ectodysplasin (Eda), which explains more than $75 \%$ of the variation in plate number between marine and freshwater fish (Colosimo et al. 2004, 2005). Most marine fish are homozygous for the "complete" Eda allele (CC) and have 30-36 plates, freshwater fish are often homozygous for the "low" allele (LL) and have 0-9 plates, and heterozygotes (CL), rare in both habitats, have an intermediate number of plates. The low allele, estimated to be 2 million years old, is present in low frequencies $(\sim 1 \%)$ in marine populations, suggesting that freshwater populations, which form a monophyletic group at $E d a$, used standing genetic variation to adapt to the novel lake habitat (Colosimo et al. 2005).

To mimic selection pressures experienced by threespine stickleback upon invasion of novel freshwater habitats, Barrett, Rogers, and Schluter (2008) created four experimental ponds into which they introduced marine fish known to be heterozygous for the low allele (CL). They then sampled and genotyped the $\mathrm{F}_{1}$ progeny of these fish (in which all three genotypic classes were present) at 10 time points over the course of 1 year. Selection coefficients were calculated from changes in genotype and allele frequencies. As expected, individuals with at least one copy of the low allele had increased growth rates and higher overwinter survival (October-July; $s=0.52$ against the $\mathrm{C}$ allele). However, contrary to expectations, the frequency of the low allele actually decreased during the summer (July-October; $s=0.50$ against the L allele), before the development of armor plates, which suggests conflicting selection pressures on Eda or a linked gene (Fig. 1A) (Barrett et al. 2008). At present, it is unclear why complete alleles are favored in the summer, but complementary studies focusing on phenotypic change (see below) might provide insight into the precise targets of selection at different times during the year. Nevertheless, had allele frequencies only been measured at the start and end of the year, changes in the direction and intensity of selection acting on the low allele would have been missed.

\section{Phenotypes}

Because selection acts at the phenotypic level, we can estimate its strength even in the absence of any knowledge about the genetic basis of fitness-related traits. A series of papers starting in the late 1970s laid the foundation for the analysis of selection on continuously varying phenotypic traits (Lande 1979; Lande and Arnold 1983; Arnold and Wade 1984a,b). Under this quantitative genetic approach (also referred to as the "Chicago School" approach), the mode and intensity of natural selection are estimated by regressing relative fitness (for continuous traits, fitness is typically calculated relative to the population mean) onto phenotypic values. Directional selection is characterized by a linear relationship between fitness and phenotype, and the slope of this relationship, calculated using linear regression, estimates the strength of selection (i.e., change in phenotypic means that is due to selection). When phenotypic values are standardized by subtracting the population mean and dividing by the population standard deviation, the slope of the phenotype-fitness regression equals the selection differential $(S)$, which is defined as the covariance between fitness and the trait $(\operatorname{Cov}[w, z])$ (Price 1970). 
A

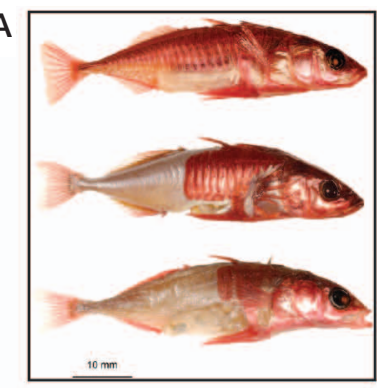

Phenotype

B

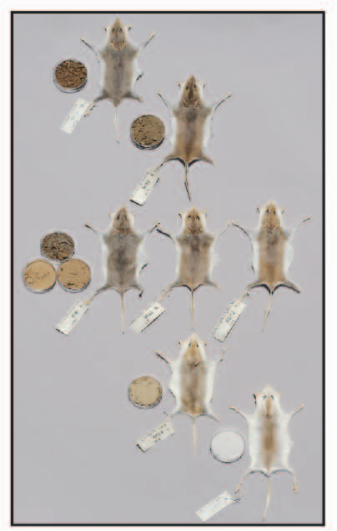

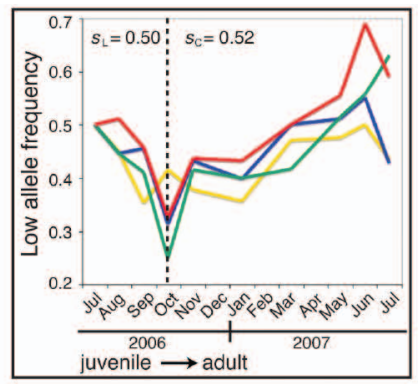

Genotype
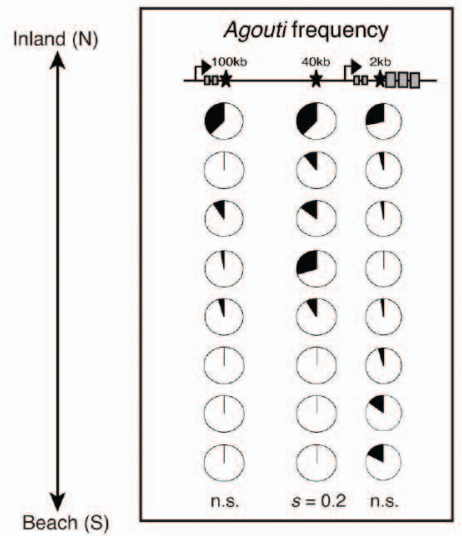

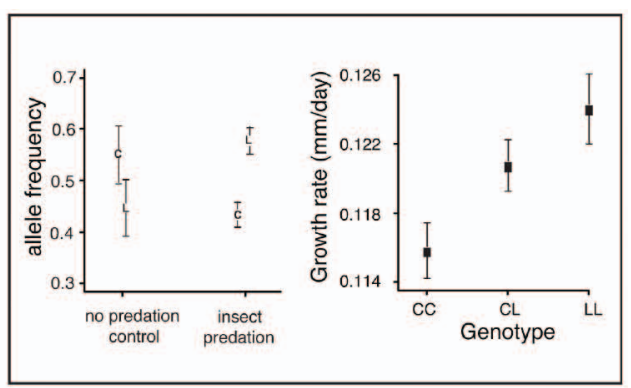

Agent of Selection

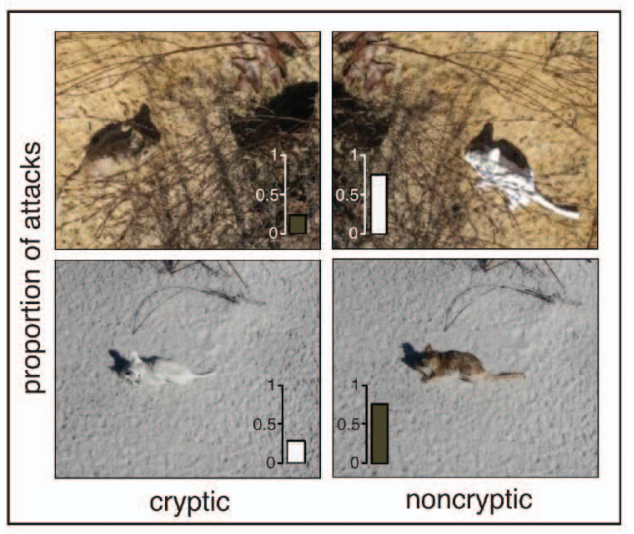

Figure 1. Two examples for which both the targets (phenotypic and genotypic) and agents of natural selection have been identified. (A) Selection on body armor in the threespine stickleback, Gasterosteus aculeatus. (Left panel) Complete (top), partial (middle), and low (bottom) lateral plate morphs. (Middle panel) Changes in low Eda allele frequency within a single generation in four replicate ponds (colored lines). Selection coefficients are given for selection against the low allele from July to October $\left(s_{\mathrm{L}}\right)$ and from selection against the complete allele from October to July $\left(s_{\mathrm{C}}\right)$. (Right panel) Relative to the complete Eda allele $(\mathrm{C})$, individuals carrying the low Eda allele (L) enjoy decreased predation by insects (left) and increased growth rates in fresh water (right). (B) Selection on coat color in the oldfield mouse Peromyscus polionotus. (Left panel) Representative mice and soil sampled from collection sites along a $150-\mathrm{km}$ transect from northwestern Florida (beach) to southeastern Alabama (inland). (Middle panel) Allele frequencies at three polymorphic sites (stars) within the pigmentation gene Agouti (large boxes: coding exons; small boxes: untranslated exons) sampled from eight populations along the same N-S transect. Pie charts and mice are arranged N (top) to S (bottom) and light allele frequencies are indicated in white. One of the three single-nucleotide polymorphisms (SNPs) $(40 \mathrm{~kb})$, but not the others, varies clinally. The selection coefficient is given for this SNP. (Right panel) Increased attack rates on noncryptic clay models relative to cryptic clay models on both light (beach) and dark (inland) soils demonstrate that visually hunting predators are an important selective agent targeting color variation within and between P. polionotus populations. (A [left and middle panels], Reprinted, with permission, from Barrett et al. 2008 [C AAAS]; A [right panel, left], reprinted, with permission, from Marchinko 2009; A [right panel, right], modified, with permission, from Barrett et al. 2009; $B$ [left panel], reprinted, with permission, from Mullen and Hoekstra 2008; $B$ [middle panel], modified, with permission, from Mullen and Hoekstra 2008; B [right panel], modified, with permission, from Vignieri et al. 2010 [all @ Wiley].)

Standardizing data also provides selection estimates that are comparable across different traits and organisms (Kingsolver et al. 2001).

Selection differentials measure total selection on a given trait. However, phenotypes can be correlated with fitness either because they impact fitness directly (direct selection) or because they are correlated with other traits that affect fitness (indirect selection). Selection gradients $(\beta)$, in contrast, are calculated using multiple regression to control for indirect selection, thereby estimating direct selection on a trait (Lande and Arnold 1983). Selection gradient analysis has now been applied to a wide range of plant and animal taxa (compiled in Endler 1986; Hoekstra et al. 2001; Kingsolver et al. 2001; Siepielski et al. 2009). In most cases studied to date, estimates of $\beta$ and $S$ are similar, suggesting that, for the traits that were investigated, indirect selection is usually small relative to direct selection (Kingsolver et al. 2001). This observation, however, does not suggest that indirect selection is low or unimportant, but rather that we tend to focus on traits for which we have a priori reasons to believe are targets of selection. In fact, strong indirect selection can overcome direct selection in an opposing direction, and selection gradients and differentials will have opposite signs. These cases - the most famous of which involves Darwin's finches - illustrate the importance of measuring multiple traits and estimating both direct and total selection to gain an accurate picture of adaptation and evolutionary constraint in natural populations.

Every year since 1973, Peter and Rosemary Grant and colleagues have measured survival, reproduction, and phenotypes of marked individuals of Geospiza fortis (medium ground finch) living on the Galápagos of 
Daphne Major (Grant and Grant 2002; for review, see Grant 2003; Grant and Grant 2008). From 1976 to 1977, a severe drought decimated seed supplies on the island, resulting in no reproduction and high adult mortality. During this time, virtually the only type of food available was large, hard seeds, which are most efficiently handled by large birds with deep beaks (Boag and Grant 1981; Grant 1981; Price et al. 1984). Estimates of the selection differential $(S)$ obtained by comparing phenotypic means before and after the drought confirmed that selection indeed favored birds with large bodies $(S=0.74)$ and beaks ( $S=0.53$ to 0.63 , depending on beak trait). However, because phenotypic correlations were taken into account, they found that although direct selection $(\beta)$ favored a decrease in beak length and width $(\beta=-0.14$ and -0.45 , respectively), these trait values nevertheless increased due to strong positive correlations with beak depth (Fig. 2A) (Price et al. 1984; Grant and Grant 1995). A second drought from 1984 to 1986 also resulted in decreased food supplies and high adult mortality; however, this drought followed an exceptionally wet season that resulted in an increased abundance of small, soft seeds. During this environmental perturbation, selection differentials for body $(S=-0.11)$ and beak $(S=-0.03$ to $-0.17)$ size were uniformly negative, even though direct selection favored an increase in beak length $(\beta=0.25)$ (Fig. 2A) (Gibbs and Grant 1987; Grant and Grant 1995). Thus, in G. fortis, the strength and direction of selection can vary greatly from one year to the next, and due to phenotypic correlations, the direct targets of selection need not always change in the expected direction. Such longterm field studies are rare, but they are invaluable for understanding changes in phenotype over time.

\section{CHANGES IN ALLELE FREQUENCIES OR TRAIT MEANS OVER TIME (BETWEEN GENERATIONS)}

The magnitude of the phenotypic response to selection depends on both the heritability and the strength of selection. Therefore, observed changes in allele frequencies or phenotypic means over multiple generations, when coupled with information on the relationship between genotype and phenotype, can be used to estimate the strength of selection. This approach is especially useful for organ-
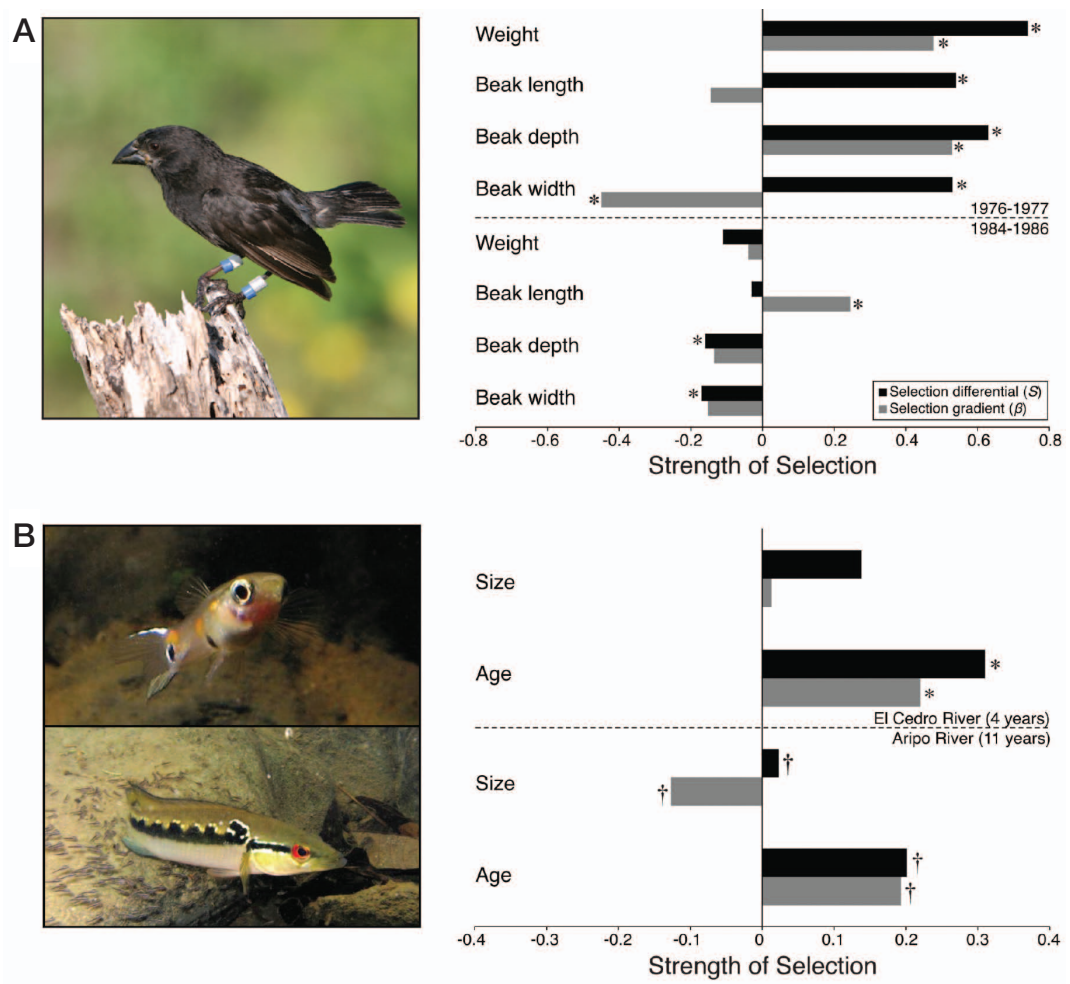

Figure 2. Strength of selection can vary in time and space, and indirect selection (via genetic correlations) can oppose direct selection on traits, as shown in Darwin's finches and Trinidadian guppies. $(A)$ Selection differentials $(S)$ and gradients $(\beta)$ for four traits in medium ground finches (Geospiza fortis) calculated from changes in phenotypic means (within generation) following two bouts of selection (1976-1977 and 1984-1986 droughts). Asterisks indicate $S$ and $\beta$ that are significantly different from zero $(p<0.05)$. (B) Selection differentials $(S)$ and gradients $(\beta)$ for age and size at maturity in male guppies (Poecilia reticulata) calculated from response to selection (between generations) under low-predation conditions in two streams (El Cedro River and Aripo River). Results are from bivariate analyses, and asterisks indicate values significantly different from zero. The significance of bivariate Aripo River estimates (denoted by $\dagger$ ) could not be evaluated, but these estimates were significantly different from zero in a univariate analysis. Photos are a male guppy (top) and its chief predator, the pike cichlid (Crenicichla alta) (bottom). (A, Data from Grant and Grant 1995 [photo by B.R. Grant]; B, data from Reznick et al. 1997 [photos by P. Bentzen].) 
isms for which it is difficult or impossible to track differences in survival and/or reproduction among a cohort of individuals. For example, although we usually cannot measure fitness in long-dead organisms preserved as ancient DNA samples or in natural history collections, these resources provide us with invaluable time-series data on allele frequencies and/or phenotypic means that can be used to estimate selection.

\section{Genotypes}

Simple population genetic models predict changes in allele frequencies after one generation of selection. If $p$ and $q$ are the frequencies of alleles $A$ and $B ; w_{A A}, w_{A B}$, and $w_{B B}$ are the relative fitnesses of genotypes $A A, A B$, and $B B$; and $\bar{w}$ is the mean fitness of the population, then change in the frequency of the $A$ allele $\left(\Delta p=p^{\prime}-p\right)$, is given by

$$
\Delta p=\frac{p q\left[p\left(w_{A A}-w_{A B}\right)+q\left(w_{A B}-w_{B B}\right)\right]}{\bar{w}} .
$$

Therefore, if we know allele frequencies in two consecutive generations and the degree of dominance, we can calculate the selection coefficient. For example, assuming $w_{A A}=1$ and $w_{A B}$ and $w_{B B}$ both equal $1-s$ (i.e., $A$ is recessive and $A A$ is the most fit genotype), the selection coefficient is given by

$$
s=\frac{\Delta p}{p^{\prime}\left(1-p^{2}\right)-p q} .
$$

Over multiple generations, selection generates a sigmoidal response curve of allele frequency change that can be used to estimate $s$ (Haldane 1924). Alternatively, $s$ can be estimated by running a recurrence equation over $n$ generations under alternative values of $s$, choosing the value that best explains the observed allele frequencies (Cook 2003). These approaches were used by Haldane (1924) and others (for review, see Cook 2003; see below) to estimate selection on melanic and typical forms of the iconic peppered moth Biston betularia.

More recently, Bollback et al. (2008) developed a maximum likelihood (ML) approach that uses the diffusion process (see Ewens 2004) to estimate effective population size $\left(N_{\mathrm{e}}\right)$ and selection $(s)$ from time-series data of allele frequencies. They applied this method to frequency data for the human CCR5- $\Delta 32$ mutation, which confers resistance to HIV (human immunodeficiency virus) infection, from European samples gathered from 2900 years ago to the present (Hummel et al. 2005). Contrary to previous work that reported large selection coefficients (Novembre et al. 2005), Bollback et al. (2008) found an ML estimate of $s$ near zero, which suggests that before the origin of HIV, this mutation was neutral or nearly neutral. In another ancient DNA study, Ludwig et al. (2009) applied this method to Eurasian horse samples dating from 20,000 years ago to the present. They typed fossils at six loci known to contribute to color variation in horses and found both a dramatic increase in horse coat-color variation coinciding with domestication ( $\sim 500$ years ago;
Outram et al. 2009), and, for two of the six loci, selection coefficients were significantly different from zero (agouti signaling protein [Agouti], $s=0.0007$, and melanocortin1 receptor $[M c 1 r], s=0.0019)$. These results suggest that domestication and selective breeding contributed to changes in horse coloration.

\section{Phenotypes}

Estimating the strength of phenotypic selection from multigenerational data requires information on the genetic basis of traits under selection. For quantitative traits, the standard equation for predicting evolutionary response to selection is the breeder's equation $R=h^{2} S$, where $R$ is the response to selection (i.e., change in trait mean), $h^{2}$ is narrow-sense heritability (i.e., the fraction of total phenotypic variation that is additive), and $S$ is the selection differential (Falconer and Mackay 1996). Because phenotypes are often genetically correlated, Lande (1979) developed a multivariate version of this equation that predicts evolutionary response on a trait by accounting for selection on correlated traits (and their corresponding genetic covariances) in addition to direct selection (and its genetic variance). The multivariate ana$\log$ of $R=h^{2} S$ is $\mathbf{R}=\mathbf{G} \boldsymbol{\beta}$, where $\mathbf{G}$ is the genetic variance-covariance matrix (i.e., the $\mathbf{G}$ matrix, in which diagonal elements are additive genetic variances for $n$ traits, and off-diagonal elements are additive genetic covariances between traits) and $\boldsymbol{\beta}$ is a vector of selection gradients (Lande 1979; Lande and Arnold 1983).

This eponymous equation is most commonly used by breeders to either predict phenotypic response to selection or to estimate heritability, but it can also be used to estimate phenotypic selection in nature (rearranging, $S=$ $R / h^{2}$ and $\boldsymbol{\beta}=\mathbf{R G}^{-\mathbf{1}}$ ) (Thompson 2008). Two advantages of this approach are that it allows one to estimate selection when within-generation fitness estimates are unattainable, and it takes into account the impact of trait variation on total lifetime fitness, not just a single fitness component. An important disadvantage, however, is that its accuracy is sensitive to errors in estimates of genetic variance, failure to measure all traits under selection, and/or fluctuating environmental conditions (Kruuk et al. 2008). Nonetheless, this equation has been shown to accurately predict evolutionary response, particularly when trait heritabilities are high and have narrow confidence intervals (see, e.g., Grant and Grant 1995, 2002), as is the case for life-history traits in Trinidadian guppies.

Guppies (Poecilia reticulata) living in Trinidad occur in two habitats: high-predation habitats, defined by presence of pike predator (Crenicichla alta) that selectively prey on large mature guppies, and low-predation habitats that lack this cichlid (Fig. 2B). Fish from low-predation populations mature later and at a larger size than their low-predation counterparts, and these differences are genetically based (Reznick 1982; Reznick and Endler 1982). To test if these differences are caused by selection, Reznick et al. (1997) moved guppies from two high-predation to two low-predation streams. After 4-11 years of selection, they quantified phenotypic response (change in mean size and age at 
maturity), heritabilities, and $\mathbf{G}$ matrices for fish in each of the two streams and used these values to calculate $S$ and $\beta$. As predicted, both size and age at reproductive maturity increased (size, $S=0.023$ and 0.138; age, $S=0.201$ and 0.310, for Aripo and El Cedro, respectively) once fish were freed from predation pressure. In both streams, there was strong direct selection for increased age at maturity, and selection on age exceeded selection on size (size, $\beta=$ -0.127 and 0.013 ; age, $\beta=0.193$ and 0.220 , for Aripo and El Cedro, respectively). However, in the Aripo River, but not in the El Cedro River, there was selection for a decrease in size at maturity (Fig. 2B). These differences likely stem from the different genetic compositions of the starting populations and/or ecological differences between the two streams. Like the threespine stickleback example, this work demonstrates the importance of replication to detect unique and shared responses to novel selection pressures; like the Darwin's finch example, this work highlights the importance of measuring both direct and total (direct + indirect) phenotypic selection.

\section{SPATIAL PATTERNS OF ALLELE FREQUENCIES AND PHENOTYPE MEANS}

The spatial distribution of genotypes and phenotypes can tell us a great deal about the strength of natural selection maintaining patterns of geographic variation (Haldane 1948; Slatkin 1973, 1975; Endler 1977; Barton 1979a,b, 1983; Barton and Hewitt 1985). For example, sharp transitions in allele frequencies or trait means, particularly if they coincide with ecotones (transition areas between adjacent ecological communities), suggest a role for selection because in the absence of selection, gene flow will homogenize populations (Haldane 1930; Lenormand 2002; Slatkin 2003). Thus, the frequency of alleles in adjacent populations, and the sharpness of the transition between them, is determined by both the amount of gene flow and the strength of selection against deleterious alleles in each habitat. When gene flow and selection reach an equilibrium, the populations are considered to be in migration-selection balance. A mathematical model of migration-selection balance was proposed by Haldane (1930) and Wright (1931), who showed that the change in the deleterious (immigrant) allele frequency in a population $(\Delta q)$ is given by

$$
\Delta q=\frac{-s p q[q+h(p-q)]}{1-s q(2 h p+q)}+m Q-M q
$$

in which $s$ is the selection coefficient against the deleterious allele, $q$ and $p$ are allele frequencies of the deleterious and nondeleterious alleles, $h$ is the dominance coefficient, $m$ is the migration rate into the population, $Q$ is the frequency of the deleterious allele outside the population, and $M$ is the emigration rate. Using this approach, Hoekstra et al. (2004) estimated the strength of selection acting on allelic variation at a single locus $(M c 1 r)$ that determines coat color in pocket mice (Chaetodipus intermedius) living on light- and dark-colored rocks in the southwestern United States. They reported strong selection for background matching but found that selection estimates were not symmetrical-light mice were more strongly selected against on dark rock $(s=0.013-0.390)$ than dark mice on light rock ( $s=0.0002-0.020)$. This is consistent with visual perception abilities of avian predators, with selection on light/melanic forms of peppered moths (Cook and Mani 1980), and with the direction of evolutionary change (i.e., light mice colonized newly formed lava flows, and strong selection against these mismatched mice favored the evolution of the novel melanic form).

As shown, Equation 3 can be used for populations sampled from two distinct habitats. Alternatively, when multiple populations are sampled along an ecotone, the distance over which allele frequencies or trait means change (i.e., the cline width $[w]$ ) can be used to estimate selection $(s)$ because $w$ is proportional to $\sigma / \sqrt{s}$, where $\sigma$ is the standard deviation of the adult-offspring dispersal distance (Haldane 1948; Slatkin 1973). Cline width is estimated by fitting a sigmoidal curve to allele frequencies or population trait means plotted as a function of geographic distance. The cline width is defined as the inverse of the maximum slope of this curve for allele frequencies; for quantitative traits, cline width is equal to $\Delta z /(\delta z / \delta x)$, where $\Delta z$ is the difference in population means on either side of the cline and $\delta z / \delta x$ is the maximum slope of phenotypic change over distance $x$ (Slatkin 1978; Barton and Gale 1993). This approach has been used widely to analyze clines in allele frequencies (see, e.g., Mallet et al. 1990) and quantitative traits (see, e.g., Nurnberger et al. 1995), but only rarely are genotypes and phenotypes analyzed together. One notable exception is the work of Mullen and Hoekstra (2008), who took advantage of knowing the genetic basis of pigment variation to analyze selection acting to maintain both a cline in pigmentation and its underlying genes (Fig. 1B).

In the southeastern United States, there is a sharp transition in soil color from the white sandy beaches of Florida to darker inland soils. In the 1920s, Francis Sumner sampled oldfield mice (Peromyscus polionotus) along a 150$\mathrm{km}$ transect and found that as he moved inland and the soil got darker, pale-colored mice were replaced by a darker form more typical of the genus (Sumner 1929a,b). Using Sumner's original museum specimens, Mullen and Hoekstra (2008) quantified brightness over multiple body regions with a spectrophotometer. From these phenotypic data and estimates of dispersal distances in P. polionotus, they calculated the width of the cline and strength of selection; selection on coat color was strong (assuming an ecotonal model, $s=0.07-0.21$, depending on body region measured). In addition, because previous work had identified two genes (Mclr and Agouti) that contribute to pigment differences in these mice (Hoekstra et al. 2006; Steiner et al. 2007), they were able to estimate cline widths and selection strengths for these alleles (Fig. 1B). Although a single molecular marker in the Agouti locus showed clinal variation similar to that observed for phenotypes (cline width, and therefore selection strength, was statistically indistinguishable from the phenotypic cline, $s$ $=\sim 0.2$ ), allelic variation at $M c 1 r$ showed a surprising lack of clinal variation. This was due to dark mice harboring 
"light" Mclr alleles in the northernmost populations. One explanation for this pattern is that epistatically interacting alleles (e.g., Agouti) (Steiner et al. 2007) mask the effects of $M c l r$ and therefore relax selection against the light $M c 1 r$ allele when on a dark Agouti genetic background (common in dark soil habitats). Additional data are needed to test this hypothesis, but these results clearly show how selection on both phenotypes and genotypes may vary in strength and direction across different environments and sometimes in complex ways.

\section{SELECTION ESTIMATES BASED ON DNA SEQUENCE DATA}

With recent advances in genomic technologies and powerful new statistical methods for linking genotype to phenotype in natural populations has come an explosion of methods for detecting natural selection at the molecular level (for review, see Nielsen 2005; Biswas and Akey 2006; Eyre-Walker 2006; Sabeti et al. 2006; Jensen et al. 2007b; Thornton et al. 2007; Grossman et al. 2010). Natural selection shapes the distribution of alleles within and between populations and species; thus, both population-genetic and comparative data - analyzed jointly or in isolation-can be used to infer selection. Two general approaches use these data. Many recent studies have taken a bottom-up approach in which genome-scale sequence data are screened for signatures of selection, either to estimate the proportion of the genome affected by selection (for review, see Eyre-Walker 2006; Sella et al. 2009) or to identify promising loci for future functional (and ecological) verification (see, e.g., Nielsen et al. 2005; Williamson et al. 2007; Grossman et al. 2010). Here, we focus on the top-down approach, in which the evidence for selection is evaluated for a candidate gene (or mutation) chosen a priori based on its known effects on an individual's phenotype (and, ideally, fitness) (see, e.g., Bersaglieri et al. 2004; Olsen et al. 2007; Pool and Aquadro 2007; Linnen et al. 2009). Because methods for detecting selection have been recently and thoroughly reviewed, we give a brief overview of some more widely used approaches, with particular emphasis on how these methods can be used to obtain quantitative estimates of $s$ (or related parameters).

When a novel mutation is fixed in a population by natural selection, linked neutral variation is carried along with it. Numerous methods for detecting and measuring selection are based on the characteristic patterns of variation created by this "hitchhiking" effect (Maynard Smith and Haigh 1974). Specifically, selective sweeps are expected to reduce heterozygosity surrounding a selected site while producing an excess of low- and high-frequency-derived alleles surrounding the target of selection (i.e., a U-shaped site-frequency spectrum [SFS]) (Tajima 1989; Fu and Li 1993; Braverman et al. 1995; Fu 1997; Fay and Wu 2000). On the basis of these predictions, Kim and Stephan (2002) developed a model-based approach that uses a composite likelihood ratio (CLR) test to compare the likelihood of polymorphism data under the standard neutral model to the likelihood of the data under a hitchhiking model. Because sweeps are also expected to affect patterns of linkage disequilibrium (LD) - for example, strong LD is expected on either side of a beneficial mutation but not across the two sides-Kim and Nielsen (2004) later extended this method to include information regarding LD (see also Sabeti et al. 2002; Stephan et al. 2006; Jensen et al. 2007a). Both approaches generate ML estimates of the strength and target of selection under the hitchhiking model. In addition, although the CLR test assumes that the swept allele has gone to fixation, Meiklejohn et al. (2004) demonstrated that this test can also be applied to incomplete sweeps by analyzing only those chromosomes that carry the beneficial allele. Linnen et al. (2009) used this strategy to estimate the strength of selection acting on a partially swept allele contributing to adaptive coloration in deer mice (Peromyscus maniculatus) living on the light soils of the Nebraska Sand Hills (Fig. 3). On the basis of this analysis, they concluded that selection for light color is relatively strong ( $s$ $=0.006$ ), comparable in magnitude to estimates of $s$ obtained for color polymorphisms in other organisms (compiled by Hoekstra et al. 2004).

Whereas polymorphism-based methods such as the CLR test estimate the strength of very recent selection acting on individual mutations (i.e., $\sim 0.4 N$ generations or less since the fixation of an allele) (see Kim and Stephan 2002; Przeworski 2002), methods that use comparative (between-species) data, either in addition to or in the absence of within-species data, calculate the average strength of selection acting on a particular locus (or site; see Fitch et al. 1997; Nielsen and Yang 1998; Suzuki and Gojobori 1999) over longer periods of evolutionary time. The most widely used of these are the Hudson-KreitmanAguade (HKA) test (Hudson et al. 1987), the McDonaldKreitman (MK) test (McDonald and Kreitman 1991), and $\mathrm{d}_{\mathrm{N}} / \mathrm{d}_{\mathrm{S}}$-based tests (Kimura 1977; Yang and Bielawski 2000). The HKA test is based on the expectation that, under neutrality, the ratio of intraspecific polymorphism to interspecific divergence will be equal across loci (Kimura 1983). Selection is inferred when there are significant differences in polymorphism-to-divergence ratios among loci. As it is typically implemented, the HKA test does not provide estimates for the strength of selection. Quantitative estimates can be obtained, however, using an ML alternative to the standard HKA test that was developed by Wright and Charlesworth (2004).

The MK test also uses interspecific and intraspecific data, but it differs from the HKA test in that it partitions data into functional classes and can be applied to data from a single locus. This test is most often applied to proteincoding regions (but see Andolfatto 2005; Pollard et al. 2006; Hahn 2007), for which the ratio of nonsynonymous to synonymous polymorphisms within a species is compared to the ratio of nonsynonymous to synonymous differences between species; a significant difference in these ratios implicates selection. Sawyer and Hartl (1992) developed an explicit mathematical framework-the Poisson Random Field - that provides an estimate of the average selection coefficient for a locus from an MK table (see also Bustamante et al. 2002, 2005; Sawyer et al. 2003, 
A

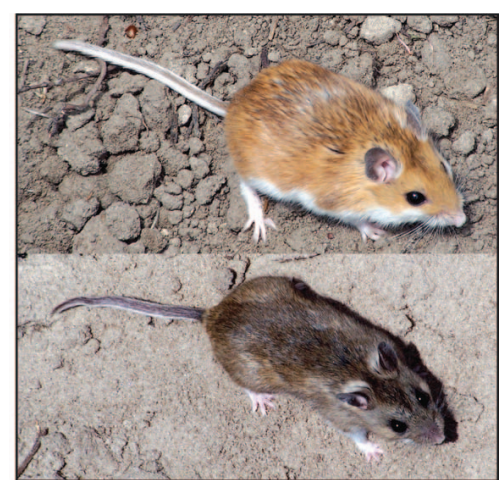

B

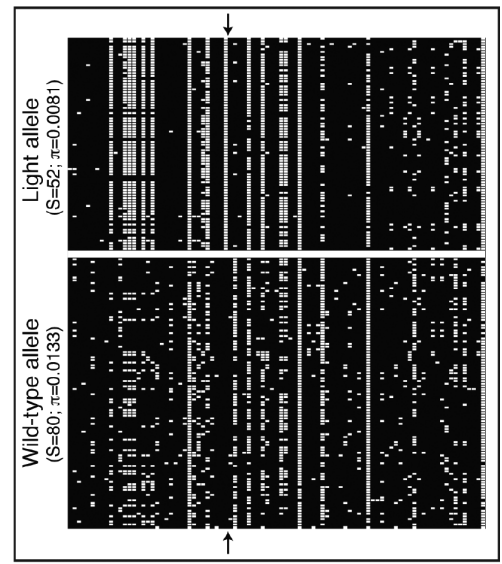

C

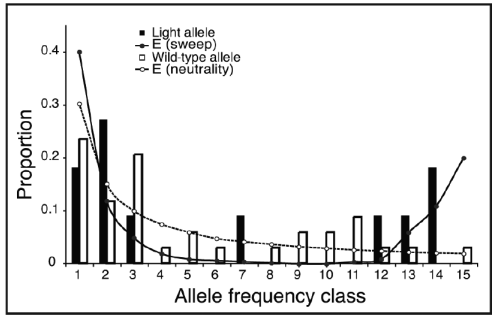

D

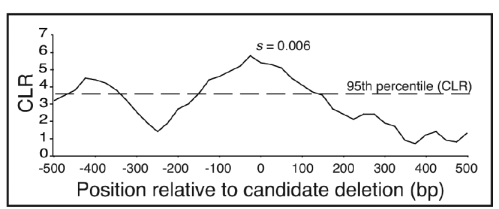

Figure 3. Molecular evidence of a partial selective sweep on the light-color allele in deer mice Peromyscus maniculatus. (A) Deer mice living on the pale soils of the Nebraska Sand Hills are lighter (top) than deer mice from darker surrounding areas (bottom). Mice are shown on contrasting soil backgrounds (bottom: Sand Hills soil; top: soil from outside the Sand Hills). (B) Consistent with patterns expected under recent selection on a de novo mutation, variation among light Agouti haplotypes is reduced compared to variation among wild-type haplotypes. $(C)$ Site-frequency spectrum (SFS) for the light Agouti allele matches patterns expected under a selective sweep (black circles and solid line), whereas the SFS for the wild-type allele matches neutral expectations (white circles/dashed line). (D) Composite likelihood ratio (CLR) as a function of distance from candidate polymorphism within Agouti for the light allele. Values above the line reject the neutral model, and the maximum CLR value, which indicates the putative target of selection, is near the candidate deletion. An estimate of the selection coefficient $(s)$, obtained by maximization of the composite likelihood function, is given. ( $A$, Photos by E. Kay; $A, B$, reprinted, with permission, from Linnen et al. 2009 [C AAAS]; $C$, data from Linnen et al. 2009; $D$, modified from Linnen et al. 2009.)
2007; Eyre-Walker 2006; Andolfatto 2007). Like the MK test, $\mathrm{d}_{\mathrm{N}} / \mathrm{d}_{\mathrm{S}}$ tests partition data into functional classes. Specifically, these tests compare the rate of nonsynonymous substitutions $\left(\mathrm{d}_{\mathrm{N}}\right)$ to the rate of synonomous substitutions $\left(\mathrm{d}_{\mathrm{s}}\right)$, with the expectation that $\mathrm{d}_{\mathrm{N}} / \mathrm{d}_{\mathrm{S}}=1$ under neutrality, $\mathrm{d}_{\mathrm{N}} / \mathrm{d}_{\mathrm{S}}>1$ under positive selection, and $\mathrm{d}_{\mathrm{N}} / \mathrm{d}_{\mathrm{S}}<1$ under negative selection. This approach differs from the MK test in that only comparative data (fixed differences between species) are used. Using an approach similar to that of Sawyer and Hartl (1992), Nielsen and Yang (2003) devised a method to estimate the distribution of selection coefficients $s$ for a given locus from $\mathrm{d}_{\mathrm{N}} / \mathrm{d}_{\mathrm{S}}$ data.

One important consideration for applying molecular tests of selection is that in some cases, observed deviations from the standard neutral model may be due to demography, not selection. Fortunately, divergence-based methods are expected to be relatively insensitive to demographic assumptions (Nielsen 2005; Garrigan et al. 2010; but see Eyre-Walker 2002; Ingvarsson 2004). In contrast, a variety of demographic scenarios can replicate patterns of genetic variation expected under hitchhiking (Tajima 1989; Fu and Li 1993; Wakeley and Aliacar 2001; Jensen et al. 2005, 2007b; Thornton and Andolfatto 2006; Thornton et al. 2007). For example, Jensen et al. (2005) demonstrated that the CLR test produces many false positives (up to 90\%) when there is population structure and/or a recent population bottleneck. They therefore developed a goodness-offit test that can be used in conjunction with the CLR test to reduce the number of false positives. An alternative approach is to estimate demographic parameters and incorporate these into comparisons between neutral and selected models (Thornton and Andolfatto 2006; Thornton and Jensen 2007; Nielsen et al. 2009). In addition to improving the false-positive rate, this approach also should yield more accurate estimates of $s$. A final consideration is that deviations from the classic hitchhiking model (Maynard Smith and Haigh 1974; Kaplan et al. 1989), such as selection on standing genetic variation (see, e.g., Hermisson and Pennings 2005; Przeworski et al. 2005), recurrent mutation (see, e.g., Pennings and Hermisson 2006a,b), or recurrent selective sweeps (see, e.g., Kim 2006; Jensen et al. 2008), also will impact our ability to detect and measure selection using population-genetic data. Nonetheless, as statistical methods continue to improve, we will be able to estimate selection under a broader range of demographic and selective scenarios.

\section{IDENTIFYING THE AGENT OF SELECTION}

Estimating the strength of selection acting on phenotypic and genotypic "targets" can clearly tell us a great deal about adaptation. However, a complete understanding of this process also requires that we determine why phenotypes and genotypes are under selection; in other words, we must identify the "agents" of natural selection in addition to its "targets" (Endler 1986; Conner 1996; Conner and Hartl 2004). When a significant relationship between phenotype (or genotype) and fitness is observed, it is always possible that this relationship is due (partially or completely) to correlation with an unmeasured charac- 
ter. Although measuring multiple traits may increase our confidence that such a scenario is unlikely, determining causation ultimately requires that we generate and test adaptive hypotheses. For example, recent experimental work reveals two reasons why selection favors the $E d a$ low allele when threespine stickleback invade freshwater habitats (see Fig. 1A). First, due to a tradeoff between armoring and growth in freshwater, fish carrying the low allele experience increased growth rates, which leads to higher overwinter survival and reproductive success (Marchinko and Schluter 2007; Barrett et al. 2008, 2009). Second, juvenile fish carrying the low allele enjoy reduced predation by insects, possibly because these fish have shorter dorsal spines, thereby reducing the ability of insects to hold and consume them (Marchinko 2009). Together, this work suggests that multiple agents of selection can favor the same genetic target.

In some cases, experimental manipulation also can yield direct estimates of the strength of selection. As discussed above, the striking match between coat color and local soil color in Peromyscus populations has long been hypothesized to be the result of selection for crypsis. In a classic experiment, Dice (1947) released equal frequencies of lab-reared deer mice with light or dark coats into enclosures that varied in substrate color and then subjected them to owl predation. He found that, as predicted, conspicuous mice were captured at much higher rates. He also devised a selection index (SI) to describe the relative survival of two equally abundant phenotypes:

$$
S I=\frac{(a-b)}{(a+b)},
$$

in which $a$ and $b$ are the number of attacked individuals in each phenotypic class. The significance of the SI can be tested using a $\chi^{2}$ test, as described by Dice $(1947,1949)$. Although Dice's experiments imply that predation may be an important agent of selection and that color is a target, his SI estimates $(0.24-0.29)$ are probably overestimates and not directly comparable to estimates from natural populations because both predator and prey densities are inflated in his experimental enclosures.

To estimate the magnitude of selection for crypsis in nature - and to control for possible selection on correlated traits, such as odor, activity level, or escape behavior-
Vignieri et al. (2010) constructed clay models of $P$. polionotus and painted these to resemble either the dark oldfield mouse (P. p. subgriseus) or the light Santa Rosa Island beach mouse (P. p. leucocephalus). They then deployed these models in beach (light) and inland (dark) habitats known to be occupied by $P$. polionotus and recorded the number of attacks - inferred from the presence of predatory marks, such as tooth or beak marks from mammals and birds - on each model type in each habitat. Across both habitats, conspicuous models were more than three times more likely to be attacked than cryptic ones (SI $=0.5$, a value even higher than that in Dice's experiments), demonstrating that both the agent (visually hunting predators) and the target (cryptic coloration) of selection had been correctly identified (Fig. 1B). Still another way to control for selection on traits other than color that may differ between beach and inland mice would be to take advantage of our ability to cross these subspecies and thus to introgress pigment alleles onto a common genetic background. If these hybrid mice were released in natural enclosures, one could estimate and compare selection estimates on individual alleles (e.g., similar to the pond experiments conducted in sticklebacks), combinations of alleles, and phenotypes.

\section{INTEGRATION ACROSS LEVELS AND TIMESCALES OF SELECTION}

The methods described here use different types of data and rely on different biological assumptions. These studies generate estimates of selection at multiple levels - from phenotypes to genotypes, and in some cases on singlenucleotide changes (Fig. 4A). And they are applicable at different timescales - estimates based on fitness or allele frequency data correspond to ecological time (one to tens of generations), methods that use neutral polymorphism data (e.g., CLR test) detect ongoing or recent selective sweeps, and comparative methods detect repeated bouts of selection over long periods of evolutionary time (Fig. 4B). Thus, we can make three types of comparisons among these methods: (1) between estimates calculated at the same level and timescale, but using different data and methods, (2) across different levels of selection (phenotypes and underlying genotypes), and (3) across different
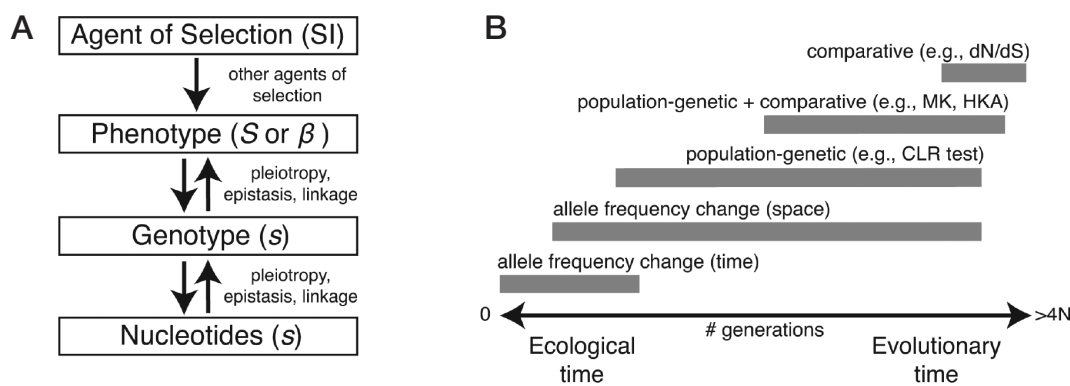

Figure 4. Comparison of selection estimates at different levels and at different timescales. $(A)$ Levels at which one can estimate selection are given in boxes with corresponding symbols in parentheses. Processes that can create discord between different levels are indicated beside arrows. (B) Approximate timescales (gray boxes) over which different types of data can inform selection studies. 
timescales. Such comparisons have the potential to reveal not only strengths and weaknesses of individual methods, but also novel insights into the adaptive process.

First, for a particular trait and organism, it can be advantageous to apply multiple methods to independent data sets to determine whether selection estimates are concordant; if not, these data may reveal why. This point is illustrated by research on one of the most intensively studied adaptive polymorphisms to date: melanic coloration in the peppered moth Biston betularia (for review, see Cook 2003; Saccheri et al. 2008). Following the onset of industrialization in 19th-century England, there was a rapid increase in the frequency of a melanic morph (carbonaria) in the peppered moth, an exemplar of strong selection (Haldane 1924, 1932). This trend continued until legislation to improve air quality was introduced in the $1960 \mathrm{~s}$, and the frequency of the carbonaria morph began to decline (Cook 2003). These changes appear to be driven by selection for crypsis to avoid avian predation: carbonaria is more cryptic on dark backgrounds (i.e., soot-covered trees), whereas the nonmelanic (typical) morph is more cryptic on lighter, unpolluted backgrounds (Cook 2003). Three types of data have been used to estimate selection coefficients against the carbonaria form following the decline in air pollution (and therefore dark backgrounds to rest upon): changes in allele frequencies over time, changes in allele frequencies over space, and both field and laboratory experiments involving predators. Although estimates of selection obtained from time-series and cline data are largely concordant ( $\mathrm{s}=\sim 0.1$ ), predation experiments suggest that selection against carbonaria is much stronger than the allele frequency data imply. These discrepancies led some to hypothesize a nonvisual advantage to melanics that partially counteracts predator-driven selection (Bishop 1972; Mani 1982). However, in a recent study that combines spatial and temporal data into a single analysis, Saccheri et al. (2008) found that gene flow was much higher than previously appreciated and that estimates of selection against the carbonaria form were consistent with predation experiments ( $s=\sim 0.2$ ), thereby suggesting that nonvisual selection was less important than had been supposed.

It is worth noting that, despite more than 80 years of work to estimate selection in B. betularia, the gene responsible for melanism has yet to be identified. In contrast, there are a small but growing number of ecologically relevant traits for which researchers have pinpointed the precise genetic changes responsible for phenotypic variation, thereby allowing comparisons between genotypic and phenotypic selection estimates (Fig. 4A). A particularly informative comparison comes from recent work on wild sunflower (Helianthus) hybrids (Lexer et al. 2003a,b). Molecular phylogenetic work has shown that two widespread annual sunflowers, Helianthus annuus and $H$. petiolarus, have given rise to three diploid hybrid species (Rieseberg et al. 1990; Rieseberg 1991). Each of these hybrid species occurs in "extreme" environments uninhabitable by either parental species. The prevailing explanation for this pattern is that genetic contributions from both parental species give rise to traits present in neither (i.e., transgressive traits) (Rieseberg et al. 1999). Lexer et al. (2003a,b) confirmed this hypothesis by mimicking the events that led to the formation of one hybrid species by crossing the parental forms and placing early-generation hybrids in the salt marsh habitat of the hybrid species $H$. paradoxus. In these paradoxus-like hybrids, these authors first measured the strength of directional selection acting on several transgressive characters, including mineral ion (e.g., $\mathrm{Ca}^{2+}$ and $\mathrm{Na}^{+}$) uptake (Lexer et al. 2003b). Next, they mapped multiple QTLs contributing to ion uptake and survivorship and measured the strength of selection acting on these QTLs in the salt marsh habitat (Lexer et al. 2003a). Comparison of these selection estimates reveals qualitative concordance across genotypic and phenotypic levels; QTLs contributing to phenotypic traits under selection were also selected in the same direction (Table 1). However, selection on each QTL was much higher than expected based on simple predictive equations (see Table 1) (Rieseberg and Burke 2001). This suggests that pleiotropy and/or genetic linkage is pervasive and increases selection on an individual QTL. Consistent with this hypothesis, extensive genetic correlations were observed both in this study and in a larger, greenhouse-based QTL study using the same cross design (Rieseberg et al. 2003; Lexer et al. 2005). These results also suggest that several loci with intermediate effects on fitness - not a large number of mutations of small effect or a small number of mutations of large effect - contributed to adaptation in salt marsh habitats. Thus, adaptation from standing genetic variation (a scenario for which hybrid species formation represents an extreme case) may be characterized by different patterns than adaptation from de novo mutation (Hermisson and Pennings 2005; Orr 2005; Przeworski et al. 2005).

Finally, as a recent review on the temporal dynamics of selection vividly illustrates, a third type of comparison we can make is among selection estimates obtained at different points in time (Fig. 4B). Siepielski et al. (2009) compiled a large database of temporally replicated studies of selection in natural populations and found (1) considerable variation in the strength of selection from year to year, (2) frequent reversals in the direction of selection, and (3) apparent changes in the form of selection (i.e., directional to stabilizing). These findings highlight the importance of field studies of selection that extend over multiple years (see, e.g., Grant 2003). They also raise questions regarding the trajectory of evolutionary change, which can be addressed by estimating selection acting on a particular mutation or gene at different temporal scales. For example, within-generation studies of selection on Eda (Barrett et al. 2008) could be complemented both by multigeneration studies in experimental ponds and by studies estimating the strength of selection driving the low armor-plate allele to fixation (or near fixation) in natural ponds. Similarly, if recent selection has been documented for a single mutation, comparative methods can be used to investigate the role of that gene in driving adaptive change over longer periods of evolutionary time. Comparing the average strength of selection on different genes may then reveal the degree to which they are constrained. For example, despite both genes being involved in the pigmentation pathway and capable of producing similar effects on color, mutations in $M c 1 r$ are more commonly 
Table 1. Phenotypic and Genotypic Selection Estimates

\begin{tabular}{|c|c|c|c|c|c|c|}
\hline \multirow[b]{2}{*}{ Trait } & \multirow[b]{2}{*}{ Linkage group } & \multirow[b]{2}{*}{$\operatorname{PVE}(\%)^{\mathrm{a}}$} & \multicolumn{2}{|c|}{ Phenotypic selection } & \multicolumn{2}{|c|}{ Genotypic selection } \\
\hline & & & $S^{\mathrm{b}}$ & $\beta^{\mathrm{b}}$ & Observed $s^{\mathrm{c}}$ & Expected $s^{\mathrm{d}}$ \\
\hline $\mathrm{Ca}$ & 1 & 32 & 0.062 & 0.237 & 0.126 & 0.010 \\
\hline $\mathrm{Na}$ & 4 & 15 & -0.250 & -0.289 & -0.084 & -0.019 \\
\hline $\mathrm{Na}$ & $17 \mathrm{~b}$ & 18 & -0.250 & -0.289 & -0.094 & -0.023 \\
\hline $\mathrm{Mg}$ & 4 & 17 & -0.250 & -0.289 & -0.084 & -0.021 \\
\hline
\end{tabular}

These estimates are for mineral uptake traits and corresponding QTLs in a second-generation backcross population $\left(\mathrm{BC}_{2}\right)$ of Helianthus annuus $\times$ H. petiolarus in the natural habitat of the hybrid species $H$. paradoxus.

${ }^{\text {aPercent }}$ phenotypic variance explained.

${ }^{b}$ Data from Lexer et al. 2003b.

'Data from Lexer et al. 2003a.

${ }^{d}$ Expected $s$ for a given QTL was calculated by multiplying the selection differential $(S)$ for the trait by the PVE and then dividing by two to account for diploidy (following Rieseberg and Burke 2001).

associated with natural color variation than mutations in Agouti (Hoekstra 2006; but see Kingsley et al. 2009). One explanation is that Agouti evolution is constrained because mutations in this gene have greater negative pleiotropic consequences on fitness (e.g., embryonic lethality, increased tumor susceptibility, diabetes, hyperphagia, and obesity) (Duhl et al. 1994; Siracusa 1994; Miltenberger et al. 2002), on average, than mutations to $M c 1 r$. This hypothesis predicts that, over evolutionary time, Mclr may be the target of positive selection more often than Agouti; average per-locus selection coefficients are therefore expected to be higher for Mclr than for Agouti. These predictions can be tested at multiple levels of divergence using MK, HKA, and $\mathrm{d}_{\mathrm{N}} / \mathrm{d}_{\mathrm{S}}$ tests (see, e.g., Mundy and Kelly 2006).

\section{CONCLUSIONS}

This is an exciting time in evolutionary biology. As an increasing number of genes underlying adaptive phenotypes are identified and statistical methods for estimating selection at the molecular level continue to improve, we will undoubtedly accumulate more precise estimates of selection acting on individual genes and mutations. In contrast, although the methods for estimating phenotypic selection are not new, they continue to provide important insights into how natural selection shapes the distribution of phenotypic variation in space and time. Although estimates of genotypic and phenotypic selection are each informative in their own right, comparisons across both levels, when coupled with identification of the agent(s) of selection, allow us to link genotype, phenotype, and the environment. At present, such studies are rare, but we suspect that comparisons among selection estimates - measured with different data and using distinct approaches - will ultimately provide a more complete picture of the adaptive process.

\section{ACKNOWLEDGMENTS}

We thank R. Barrett, P. Grant, R. Grant, J. Jensen, C. Lexer, J. Mallet, and D. Reznick for comments that improved this manuscript. R. Grant and D. Reznick kindly provided photographs. C.R.L. was supported by a Ruth Kirschstein National Research Service Award. Work from the Hoekstra Lab reported here was largely funded by the National Science Foundation.

\section{REFERENCES}

Andolfatto P. 2005. Adaptive evolution of non-coding DNA in Drosophila. Nature 437: 1149-1152.

Andolfatto P. 2007. Hitchhiking effects of recurrent beneficial amino acid substitutions in the Drosophila melanogaster genome. Genome Res 17: 1755-1762.

Arnold SJ, Wade MJ. 1984a. On the measurement of natural and sexual selection: Applications. Evolution 38: 720-734.

Arnold SJ, Wade MJ. 1984b. On the measurement of natural and sexual selection: Theory. Evolution 38: 709-719.

Barrett RDH, Rogers SM, Schluter D. 2008. Natural selection on a major armor gene in threespine stickleback. Science 322: 255257.

Barrett RDH, Rogers SM, Schluter D, Peichel C. 2009. Environment specific pleiotropy facilitates divergence at the Ectodysplasin locus in threespine stickleback. Evolution 63: 28312837.

Barton NH. 1979a. Gene flow past a cline. Heredity 43: 333-339.

Barton NH. 1979b. The dynamics of hybrid zones. Heredity 43: 341-359.

Barton NH. 1983. Multilocus clines. Evolution 37: 454- 471.

Barton NH, Gale KS. 1993. Genetic analysis of hybrid zones. In Hybrid zones and the evolutionary process (ed. RG Harrison), pp. 13-45. Oxford University Press, New York.

Barton NH, Hewitt GM. 1985. Analysis of hybrid zones. Annu Rev Ecol Syst 16: 113-148.

Bell MA, Foster SA. 1994. The evolutionary biology of the threespine stickleback. Oxford University Press, Oxford.

Bersaglieri T, Sabeti PC, Patterson N, Vanderploeg T, Schaffner SF, Drake JA, Rhodes M, Reich DE, Hirschhorn JN. 2004. Genetic signatures of strong recent positive selection at the lactase gene. Am J Hum Genet 74: 1111-1120.

Bishop JA. 1972. An experimental study of the cline of industrial melanism in Biston betularia (L.) (Lepidoptera) between urban Liverpool and rural north Wales. J Anim Ecol 41: 209-243.

Biswas S, Akey JM. 2006. Genomic insights into positive selection. Trends Genet 22: 437-446.

Boag PT, Grant PR. 1981. Intense natural selection in a population of Darwin's finches (Geospizinae) in the Galapagos. Science 214: 82-85.

Bollback JP, York TL, Nielsen R. 2008. Estimation of $2 N_{\mathrm{e}} s$ from temporal allele frequency data. Genetics 179: 497-502.

Braverman JM, Hudson RR, Kaplan NL, Langley CH, Stephan W. 1995. The hitchhiking effect on the site frequency spectrum of DNA polymorphisms. Genetics 140: 783-796.

Bustamante CD, Nielsen R, Sawyer SA, Olsen KM, Purugganan MD, Hartl DL. 2002. The cost of inbreeding in Arabidopsis. Nature 416: 531-534.

Bustamante CD, Fledel-Alon A, Williamson S, Nielsen R, Hubisz MT, Glanowski S, Tanenbaum DM, White TJ, Sninsky JJ, Hernandez RD, et al. 2005. Natural selection on protein-coding genes in the human genome. Nature 437: 1153-1157.

Colosimo PF, Peichel CL, Nereng K, Blackman BK, Shapiro MD, Schluter D, Kingsley DM. 2004. The genetic architecture of par- 
allel armor plate reduction in threespine sticklebacks. PLoS Biol 2: e109.

Colosimo PF, Hosemann KE, Balabhadra S, Villarreal G, Dickson M, Grimwood J, Schmutz J, Myers RM, Schluter D, Kingsley DM. 2005. Widespread parallel evolution in sticklebacks by repeated fixation of ectodysplasin alleles. Science 307: 19281933.

Conner JK. 1996. Understanding natural selection: An approach integrating selection gradients, multiplicative fitness components, and path analysis. Ethol Ecol Evol 8: 387-397.

Conner JK, Hartl DL. 2004. A primer of ecological genetics. Sinauer, Sunderland, MA.

Cook LM. 2003. The rise and fall of the carbonaria form of the peppered moth. Q Rev Biol 78: 399-417.

Cook LM, Mani GS. 1980. A migration-selection model for the morph frequency variation in the peppered moth over England and Wales. Biol J Linn Soc 13: 179-198.

Darwin C. 1859. On the origin of species by means of natural selection, or the preservation of favoured races in the struggle for life. John Murray, London.

De Jong G. 1994. The fitness of fitness concepts and the description of natural selection. Q Rev Biol 69: 3-29.

Dice LR. 1947. Effectiveness of selection by owls of deer-mice (Peromyscus maniculatus) which contrast in color with their background. Contrib Lab Vertebrate Biol Univ Michigan 34: 120.

Dice LR. 1949. The selection index and its test of significance. Evolution 3: 262-265.

Duhl DM, Vrieling H, Miller KA, Wolff GL, Barsh GS. 1994. Neomorphic agouti mutations in obese yellow mice. Nat Genet 8: 59-65.

Eanes WF. 1999. Analysis of selection on enzyme polymorphisms. Annu Rev Ecol Syst 30: 301-326.

Ehrenreich IM, Purugganan MD. 2006. The molecular genetic basis of plant adaptation. Am J Bot 93: 953-962.

Ellegren H, Sheldon BC. 2008. Genetic basis of fitness differences in natural populations. Nature 452: 169-175.

Endler JA. 1977. Geographic variation, speciation, and clines. Princeton University Press, Princeton, NJ.

Endler JA. 1986. Natural selection in the wild (Monographs in Population Biology). Princeton University Press, Princeton, NJ.

Erickson DL, Fenster CB, Stenoien HK, Price D. 2004. Quantitative trait locus analyses and the study of evolutionary process. Mol Ecol 13: 2505-2522.

Ewens WJ. 2004. Mathematical population genetics. Springer, New York

Eyre-Walker A. 2002. Changing effective population size and the McDonald-Kreitman test. Genetics 162: 2017-2024.

Eyre-Walker A. 2006. The genomic rate of adaptive evolution. Trends Ecol Evol 21: 569.

Falconer DS, Mackay TFC. 1996. Introduction to quantitative genetics. Longman, Essex, England.

Fay JC, Wu C-I. 2000. Hitchhiking under positive Darwinian selection. Genetics 155: 1405-1413.

Feder ME, Mitchell-Olds T. 2003. Evolutionary and ecological functional genomics. Nat Rev Genet 4: 651-657.

Fitch WM, Bush RM, Bender CA, Cox NJ. 1997. Long term trends in the evolution of H(3) HA1 human influenza type A. Proc Natl Acad Sci 94: 7712-7718.

Fu YX. 1997. Statistical tests of neutrality of mutations against population growth, hitchhiking and background selection. Genetics 147: 915-925.

$\mathrm{Fu}$ YX, Li WH. 1993. Statistical tests of neutrality of mutations. Genetics 133: 693-709.

Garrigan D, Lewontin R, Wakeley J. 2010. Measuring the sensitivity of single-locus "neutrality tests" using a direct perturbation approach. Mol Biol Evol 27: 73-89.

Gibbs HL, Grant PR. 1987. Oscillating selection on Darwin's finches. Nature 327: 511-513.

Grant PR. 1981. The feeding of Darwin's finches on Tribulus cistoides (L.) seeds. Anim Behav 29: 785-793.

Grant BR. 2003. Evolution in Darwin's finches: A review of a study on Isla Daphne Major in the Galapagos archipelago.
Zoology 106: 255-259

Grant PR, Grant BR. 1995. Predicting microevolutionary responses to directional selection on heritable variation. Evolution 49: $241-251$.

Grant PR, Grant BR. 2002. Unpredictable evolution in a 30-year study of Darwin's finches. Science 296: 707-711.

Grant PR, Grant BR. 2008. How and why species multiply: The radiation of Darwin's finches. Princeton University Press, Princeton, NJ.

Grossman SR, Shylakhter I, Karlsson EK, Byrne EH, Morales S, Frieden G, Hostetter E, Angelino E, Garber M, Zuk O, et al. 2010. A composite of multiple signals distinguishes causal variants in regions of positive selection. Science 327: 883-886.

Hahn M. 2007. Detecting natural selection on cis-regulatory DNA. Genetica 129: 7-18.

Haldane JBS. 1924. A mathematical theory of natural and artificial selection. Trans Camb Philos Soc 23: 19-41.

Haldane JBS. 1930. A mathematical theory of natural and artificial selection. Part VI. Isolation. Proc Camb Philos Soc 26: 220-230.

Haldane JBS. 1932. The causes of evolution. Longmans, London.

Haldane JBS. 1948. The theory of a cline. J Genet 48: 277-284.

Hartl DL, Clark AG. 2007. Principles of population genetics. Sinauer, Sunderland, MA.

Hermisson J, Pennings PS. 2005. Soft sweeps: Molecular population genetics of adaptation from standing genetic variation. Genetics 169: 2335-2352.

Hoekstra HE. 2006. Genetics, development and evolution of adaptive pigmentation in vertebrates. Heredity 97: 222-234.

Hoekstra HE, Hoekstra JM, Berrigan D, Vignieri SN, Hoang A, Hill CE, Beerli P, Kingsolver JG. 2001. Strength and tempo of directional selection in the wild. Proc Natl Acad Sci 98: 9157-9160.

Hoekstra HE, Drumm KE, Nachman MW. 2004. Ecological genetics of adaptive color polymorphism in pocket mice: Geographic variation in selected and neutral genes. Evolution 58: 1329 1341

Hoekstra HE, Hirschmann RJ, Bundey RA, Insel PA, Crossland JP. 2006. A single amino acid mutation contributes to adaptive beach mouse color pattern. Science 313: 101-104.

Hoffmann AA, Willi Y. 2008. Detecting genetic responses to environmental change. Nat Rev Genet 9: 421-432.

Hudson RR, Kreitman M, Aguade M. 1987. A test of neutral molecular evolution based on nucleotide data. Genetics 116: 153-159.

Hummel S, Schmidt D, Kremeyer B, Herrmann B, Oppermann M. 2005. Detection of the CCR 5- $\triangle 32$ HIV resistance gene in Bronze Age skeletons. Genes Immun 6: 371-374.

Ingvarsson P. 2004. Population subdivision and the HudsonKreitman-Aguade test: Testing for deviations from the neutral model in organelle genomes. Genet Res 83: 31-39.

Jensen JD, Kim Y, DuMont VB, Aquadro CF, Bustamante CD. 2005. Distinguishing between selective sweeps and demography using DNA polymorphism data. Genetics 170: 1401-1410.

Jensen JD, Thornton KR, Bustamante CD, Aquadro CF. 2007a. On the utility of linkage disequilibrium as a statistic for identifying targets of positive selection in nonequilibrium populations. Genetics 176: 2371-2379.

Jensen JD, Wong A, Aquadro CF. 2007b. Approaches for identifying targets of positive selection. Trends Genet 23: 568-577.

Jensen JD, Thornton KR, Andolfatto P. 2008. An approximate Bayesian estimator suggests strong, recurrent selective sweeps in Drosophila. PLoS Genet 4: e1000198.

Kaplan NL, Hudson RR, Langley CH. 1989. The "hitchhiking effect" revisited. Genetics 123: 887-899.

Kim Y. 2006. Allele frequency distribution under recurrent selective sweeps. Genetics 172: 1967-1978.

Kim Y, Nielsen R. 2004. Linkage disequilibrium as a signature of selective sweeps. Genetics 167: 1513-1524.

Kim Y, Stephan W. 2002. Detecting a local signature of genetic hitchhiking along a recombining chromosome. Genetics 160: $765-777$.

Kimura M. 1977. Preponderance of synonymous changes as evidence for the neutral theory of molecular evolution. Nature 267: 275-276. 
Kimura M. 1983. The neutral theory of molecular evolution. Cambridge University Press, Cambridge.

Kimura M, Crow JF. 1978. Effect of overall phenotypic selection on genetic change at individual loci. Proc Natl Acad Sci 75: 6168-6171.

Kingsley EP, Manceau M, Wiley CD, Hoekstra HE. 2009. Melanism in Peromyscus is caused by independent mutations in Agouti. PLoS ONE 4: e6435.

Kingsolver JG, Hoekstra HE, Hoekstra JM, Berrigan D, Vignieri SN, Hill CE, Hoang A, Gibert P, Beerli P. 2001. The strength of phenotypic selection in natural populations. Am Nat 157: 245 261.

Kruuk LEB, Slate J, Wilson AJ. 2008. New answers for old questions: The evolutionary quantitative genetics of wild animal populations. Annu Rev Ecol Evol Syst 39: 525-548.

Lande R. 1979. Quantitative genetic analysis of multivariate evolution, applied to brain: Body size allometry. Evolution 33: 402416.

Lande R, Arnold SJ. 1983. The measurement of selection on correlated characters. Evolution 37: 1210-1226.

Lenormand T. 2002. Gene flow and the limits to natural selection. Trends Ecol Evol 17: 183-189.

Lexer C, Welch ME, Durphy JL, Rieseberg LH. 2003a. Natural selection for salt tolerance quantitative trait loci (QTLs) in wild sunflower hybrids: Implications for the origin of Helianthus paradoxus, a diploid hybrid species. Mol Ecol 12: 1225-1235.

Lexer C, Welch ME, Raymond O, Rieseberg LH, Nason J. 2003b. The origin of ecological divergence in Helianthus paradoxus (Asteraceae): Selection on transgressive characters in a novel hybrid habitat. Evolution 57: 1989-2000.

Lexer C, Rosenthal DM, Raymond O, Donovan LA, Rieseberg LH. 2005. Genetics of species differences in the wild annual sunflowers, Helianthus annuus and $H$. petiolaris. Genetics 169: 2225-2239.

Linnen CR, Kingsley EP, Jensen JD, Hoekstra HE. 2009. On the origin and spread of an adaptive allele in deer mice. Science 325: 1095-1098.

Ludwig A, Pruvost M, Reissmann M, Benecke N, Brockmann G A, Castanos P, Cieslak M, Lippold S, Llorente L, Malaspinas A$\mathrm{S}$, et al. 2009. Coat color variation at the beginning of horse domestication. Science 324: 485.

Luikart G, England PR, Tallmon D, Jordan S, Taberlet P. 2003. The power and promise of population genomics: From genotyping to genome typing. Nat Rev Genet 4: 981-994.

Mackay TFC. 2001. Quantitative trait loci in Drosophila. Nat Rev Genet 2: 11-20.

Mackay TFC, Stone EA, Ayroles JF. 2009. The genetics of quantitative traits: Challenges and prospects. Nat Rev Genet 10: 565577.

Mallet J, Barton N, Gerardo LM, Jose SC, Manuel MM, Eeley H. 1990. Estimates of selection and gene flow from measures of cline width and linkage disequilibrium in Heliconius hybrid zones. Genetics 124: 921-936.

Mani GS. 1982. A theoretical analysis of the morph frequency variation in the peppered moth over England and Wales. Biol J Linn Soc 17: 259-267.

Marchinko KB. 2009. Predation's role in repeated phenotypic and genetic divergence of armor in threespine stickleback. Evolution 63: $127-138$

Marchinko KB, Schluter D. 2007. Parallel evolution by correlated response: Lateral plate reduction in threespine stickleback. Evolution 61: 1084-1090.

Maynard Smith J, Haigh J. 1974. The hitch-hiking effect of a favourable gene. Genet Res 23: 23-35.

McDonald JH, Kreitman M. 1991. Adaptive protein evolution at the Adh locus in Drosophila. Nature 351: 652-654.

McGraw JB, Caswell H. 1996. Estimation of individual fitness from life-history data. Am Nat 147: 47-64.

Meiklejohn C, Kim Y, Hartl D, Parsch J. 2004. Identification of a locus under complex positive selection in Drosophila simulans by haplotype mapping and composite-likelihood estimation. Genetics 168: 265-279.

Milkman R. 1978. Selection differentials and selection coeffi- cients. Genetics 88: 391-403.

Miltenberger RJ, Wakamatsu K, Ito S, Woychik RP, Russell LB, Michaud EJ. 2002. Molecular and phenotypic analysis of 25 recessive, homozygous-viable alleles at the mouse Agouti locus. Genetics 160: 659-674.

Mullen LM, Hoekstra HE. 2008. Natural selection along an environmental gradient: A classic cline in mouse pigmentation. Evolution 62: 1555-1569.

Mundy NI, Kelly J. 2006. Investigation of the role of the agouti signaling protein gene $(A S I P)$ in coat color evolution in primates. Mamm Genome 17: 1205-1213.

Naish KA, Hard JJ. 2008. Bridging the gap between the genotype and the phenotype: Linking genetic variation, selection and adaptation in fishes. Fish Fisheries 9: 396-422.

Nielsen R. 2005. Molecular signatures of natural selection. Annu Rev Genet 39: 197-218.

Nielsen R, Yang Z. 1998. Likelihood models for detecting positively selected amino acid sites and applications to the HIV-1 envelope gene. Genetics 148: 929-936.

Nielsen R, Yang Z. 2003. Estimating the distribution of selection coefficients from phylogenetic data with applications to mitochondrial and viral DNA. Mol Biol Evol 20: 1231-1239.

Nielsen R, Bustamante C, Clark AG, Glanowski S, Sackton TB, Hubisz MJ, Fledel-Alon A, Tanenbaum DM, Civello D, White TJ, et al. 2005. A scan for positively selected genes in the genomes of humans and chimpanzees. PLoS Biol 3: e170.

Nielsen R, Hubisz MJ, Hellmann I, Torgerson D, Andrés AM, Albrechtsen A, Gutenkunst R, Adams MD, Cargill M, Boyko A, et al. 2009. Darwinian and demographic forces affecting human protein coding genes. Genome Res 19: 838-849.

Novembre J, Galvani AP, Slatkin M. 2005. The geographic spread of the CCR5 $\triangle 32$ HIV-resistance allele. PLoS Biol 3: e339.

Nurnberger B, Barton N, MacCallum C, Jason G, Appleby M. 1995. Natural selection on quantitative traits in the Bombina hybrid zone. Evolution 49: 1224-1238.

Olsen K, Sutherland B, Small L. 2007. Molecular evolution of the $\mathrm{Li} / \mathrm{li}$ chemical defence polymorphism in white clover (Trifolium repens L.). Mol Ecol 16: 4180-4193.

Orr HA. 2005. The genetic theory of adaptation: A brief history. Nat Rev Genet 6: 119-127.

Orr HA. 2009. Fitness and its role in evolutionary genetics. Nat Rev Genet 10: 531-539.

Outram AK, Stear NA, Bendrey R, Olsen S, Kasparov A, Zaibert V, Thorpe N, Evershed RP. 2009. The earliest horse harnessing and milking. Science 323: 1332-1335.

Pavlidis P, Hutter S, Stephan W. 2008. A population genomic approach to map recent positive selection in model species. Mol Ecol 17: 3585-3598.

Pennings PS, Hermisson J. 2006a. Soft sweeps II: Molecular population genetics of adaptation from recurrent mutation or migration. Mol Biol Evol 23: 1076-1084.

Pennings PS, Hermisson J. 2006b. Soft sweeps III: The signature of positive selection from recurrent mutation. PLoS Genet 2: e186.

Pollard KS, Salama SR, Lambert N, Lambot M-A, Coppens S, Pedersen JS, Katzman S, King B, Onodera C, Siepel A, et al. 2006. An RNA gene expressed during cortical development evolved rapidly in humans. Nature 443: 167-172.

Pool JE, Aquadro CF. 2007. The genetic basis of adaptive pigmentation variation in Drosophila melanogaster. Mol Ecol 16: 2844-2851.

Price GR. 1970. Selection and covariance. Nature 227: 520-521.

Price TD, Grant PR, Gibbs HL, Boag PT. 1984. Recurrent patterns of natural selection in a population of Darwin's finches. Nature 309: 787-789.

Przeworski M. 2002. The signature of positive selection at randomly chosen loci. Genetics 160: 1179-1189.

Przeworski M, Coop G, Wall J. 2005. The signature of positive selection on standing genetic variation. Evolution 59: 2312-2323.

Reznick D. 1982. The impact of predation on life history evolution in Trinidadian guppies: Genetic basis of observed life history patterns. Evolution 36: 1236-1250.

Reznick D, Endler JA. 1982. The impact of predation on life history evolution in Trinidadian guppies (Poecilia reticulata). 
Evolution 36: 160-177.

Reznick DN, Shaw FH, Rodd FH, Shaw RG. 1997. Evaluation of the rate of evolution in natural populations of guppies (Poecilia reticulata). Science 275: 1934-1937.

Rieseberg LH. 1991. Homoploid reticulate evolution in Helianthus (Asteraceae): Evidence from ribosomal genes. Am J Bot 78: 1218-1237.

Rieseberg LH, Burke JM. 2001. The biological reality of species: Gene flow, selection, and collective evolution. Taxon 50: 47-67.

Rieseberg LH, Carter R, Zona S. 1990. Molecular tests of the hypothesized hybrid origin of two diploid Helianthus species (Asteraceae). Evolution 44: 1498-1511.

Rieseberg LH, Archer MA, Wayne RK. 1999. Transgressive segregation, adaptation and speciation. Heredity 83: 363-372.

Rieseberg LH, Raymond O, Rosenthal DM, Lai Z, Livingstone K, Nakazato T, Durphy JL, Schwarzbach AE, Donovan LA, Lexer C. 2003. Major ecological transitions in wild sunflowers facilitated by hybridization. Science 301: 1211-1216.

Sabeti PC, Reich DE, Higgins JM, Levine HZ, Richter DJ, Schaffner SF, Gabriel SB, Platko JV, Patterson NJ, McDonald GJ, et al. 2002. Detecting recent positive selection in the human genome from haplotype structure. Nature 419: 832-837.

Sabeti PC, Schaffner SF, Fry B, Lohmueller J, Varilly P, Shamovsky O, Palma A, Mikkelsen TS, Altshuler D, Lander ES. 2006. Positive natural selection in the human lineage. Science 312: 1614 1620.

Saccheri IJ, Rousset F, Watts PC, Brakefield PM, Cook LM. 2008. Selection and gene flow on a diminishing cline of melanic peppered moths. Proc Natl Acad Sci 105: 16212-16217.

Sawyer SA, Hartl DL. 1992. Population genetics of polymorphism and divergence. Genetics 132: 1161-1176.

Sawyer S, Kulathinal R, Bustamante C, Hartl D. 2003. Bayesian analysis suggests that most amino acid replacements in Drosophila are driven by positive selection. J Mol Evol 57: S154 S164.

Sawyer SA, Parsch J, Zhang Z, Hartl DL. 2007. Prevalence of positive selection among nearly neutral amino acid replacements in Drosophila. Proc Natl Acad Sci 104: 6504-6510.

Schemske DW, Bierzychudek P. 2001. Evolution of flower color in the desert annual Linanthus parryae: Wright revisited. Evolution 55: 1269-1282.

Schemske DW, Bradshaw HD. 1999. Pollinator preference and the evolution of floral traits in monkeyflowers (Mimulus). Proc Natl Acad Sci 96: 11910-11915.

Schemske DW, Horvitz CC. 1989. Temporal variation in selection on a floral character. Evolution 43: 461-465.

Sella G, Petrov DA, Przeworski M, Andolfatto P. 2009. Pervasive natural selection in the Drosophila genome? PLoS Genet 5: e1000495.

Siepielski AM, DiBattista JD, Carlson SM. 2009. It's about time: The temporal dynamics of phenotypic selection in the wild. Ecol Lett 12: 1261-1276.

Siracusa LD. 1994. The agouti gene: Turned on to yellow. Trends Genet 10: 423-428.

Slate J, Gratten J, Beraldi D, Stapley J, Hale M, Pemberton JM. 2009. Gene mapping in the wild with SNPs: Guidelines and future directions. Genetica 136: 97-107.
Slatkin M. 1973. Gene flow and selection in a cline. Genetics 75: 733-756.

Slatkin M. 1975. Gene flow and selection in a two-locus system. Genetics 81: 787-802.

Slatkin M. 1978. Spatial patterns in the distributions of polygenic characters. J Theor Biol 70: 213-228.

Slatkin M. 2003. Gene flow in natural populations. Annu Rev Ecol Syst 16: 393-430.

Steiner CC, Weber JN, Hoekstra HE. 2007. Adaptive variation in beach mice produced by two interacting pigmentation genes. PLoS Biol 5: e219.

Stephan W, Song Y, Langley C. 2006. The hitchhiking effect on linkage disequilibrium between linked neutral loci. Genetics 172: $2647-2663$.

Stinchcombe JR, Hoekstra HE. 2008. Combining population genomics and quantitative genetics: Finding the genes underlying ecologically important traits. Heredity 100: $158-170$.

Sumner FB. 1929a. The analysis of a concrete case of intergradation between two subspecies. Proc Natl Acad Sci 15: 110-120.

Sumner FB. 1929b. The analysis of a concrete case of intergradation between two subspecies. II Additional data and interpretations. Proc Natl Acad Sci 15: 481-493.

Suzuki Y, Gojobori T. 1999. A method for detecting positive selection at single amino acid sites. Mol Biol Evol 16: 1315-1328.

Tajima F. 1989. Statistical method for testing the neutral mutation hypothesis by DNA polymorphism. Genetics 123: 585-595.

Thompson R. 2008. Estimation of quantitative genetic parameters. Proc R Soc Lond B Biol Sci 275: 679-686.

Thornton K, Andolfatto P. 2006. Approximate bayesian inference reveals evidence for a recent, severe bottleneck in a Netherlands population of Drosophila melanogaster. Genetics 172: 1607 1619.

Thornton KR, Jensen JD. 2007. Controlling the false-positive rate in multilocus genome scans for selection. Genetics 175: 737750

Thornton KR, Jensen JD, Becquet C, Andolfatto P. 2007. Progress and prospects in mapping recent selection in the genome. Heredity 98: 340-348.

Vasemagi A, Primmer CR. 2005. Challenges for identifying functionally important genetic variation: The promise of combining complementary research strategies. Mol Ecol 14: 3623-3642.

Vignieri SN, Larson JG, Hoekstra HE. 2010. The selective advantage of crypsis in mice. Evolution (in press).

Wakeley J, Aliacar N. 2001. Gene genealogies in a metapopulation. Genetics 159: 893-905.

Wallace AR. 1858. On the tendency of varieties to depart indefinitely from the original type. J Proc Linn Soc 3: 53-62.

Williamson SH, Hubisz MJ, Clark AG, Payseur BA, Bustamante CD, Nielsen R. 2007. Localizing recent adaptive evolution in the human genome. PLoS Genet. 3: e90.

Wright SJ. 1931. Evolution in Mendelian populations. Genetics 16: $97-159$.

Wright SI, Charlesworth B. 2004. The HKA test revisited: A maximum-likelihood-ratio test of the standard neutral model. Genetics 168: 1071-1076.

Yang Z, Bielawski JP. 2000. Statistical methods for detecting molecular adaptation. Trends Ecol Evol 15: 496-503. 


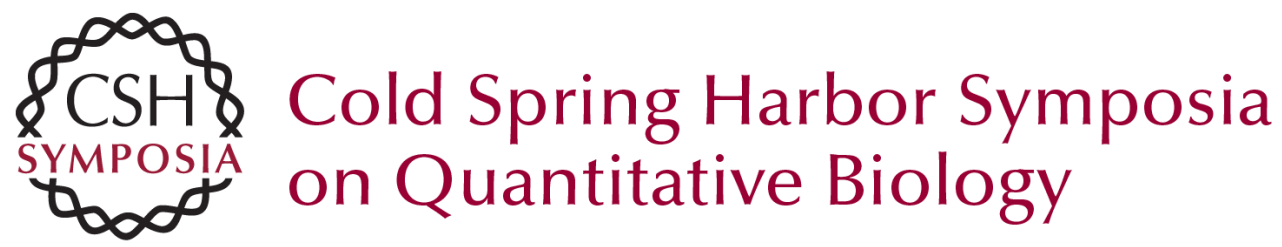

\section{Measuring Natural Selection on Genotypes and Phenotypes in the Wild}

C.R. Linnen and H.E. Hoekstra

Cold Spring Harb Symp Quant Biol 2009 74: 155-168 originally published online April 22, 2010

Access the most recent version at doi:10.1101/sqb.2009.74.045

References This article cites 158 articles, 23 of which can be accessed free at:

http://symposium.cshlp.org/content/74/155.full.html\#ref-list-1

\section{License}

Email Alerting Receive free email alerts when new articles cite this article - sign up in the box at the Service top right corner of the article or click here. 